\title{
Rendimento forrageiro e composição bromatológica de variedades de milheto (Pennisetum glaucum (L.) R. BR.) ${ }^{1}$
}

\author{
José Luiz Kollet ${ }^{2}$, José Mauro da Silva Diogo ${ }^{3}$, Gilberto Gonçalves Leite ${ }^{4}$
}

\author{
${ }^{1}$ Parte da dissertação de Mestrado do primeiro autor apresentada à UnB. Financiada pelo CNPq. \\ ${ }^{2}$ Mestrando em Ciências Agrárias Faculdade de Agronomia e Medicina Veterinária - UnB, Brasília, DF. \\ ${ }^{3}$ Faculdade de Agronomia e Medicina Veterinária - UnB, Brasília, DF. \\ ${ }^{4}$ Embrapa Cerrados, Brasília, DF.
}

RESUMO - O experimento foi realizado para avaliar a produtividade, o perfilhamento, a porcentagem de lâmina/haste e a composição bromatológica (PB, FDN e FDA) de três variedades (Africano, Americano e BN-2) de milheto (Pennisetum glaucum (L) R. Br.) em três idades de corte (35, 42 e 49 dias). Na primeira fase da pesquisa, foi utilizado delineamento experimental em blocos casualizados, em um esquema de parcelas subdivididas no tempo, com quatro repetições. Na fase de rebrota, o delineamento foi inteiramente casualizado, com o mesmo número de repetições. As parcelas principais foram representadas pelas variedades e as subparcelas, pelas três idades de corte. A produção média de MS durante a fase de corte foi similar entre as variedades (4.360, 4.204 e $3.247 \mathrm{~kg} / \mathrm{MS} / \mathrm{h}$ a para as variedades Africano, Americano e BN-2, respectivamente), ao passo que os teores de PB, FDN e FDA e a relação lâmina/haste diferiram (Americano: $16,71 \%$ PB; 56,29\% FDN e 30,04\% FDA; BN-2: 16,30\% PB; 55,93\% FDN e 30,98\% FDA; Africano: 15,36\% PB; 60,55\% FDN e 34,55\% FDA). Com o avançar da idade de corte, a produtividade e os teores de FDN e FDA aumentaram, enquanto a relação lâmina/haste e o teor de PB decresceram linearmente. Na rebrota, a produtividade diminuiu, mas os teores médios de PB, FDN e FDA não diferiram entre as variedades (Americano: 20,21\% PB; 53,19\% FDN e 26,72\% FDA; BN-2: 20,43\% PB; 53,42\% FDN e 27,06\% FDA; Africano: 19,75\% PB; 52,45\% FDN e 27,44\% FDA), observando-se diferença para a relação média lâmina/haste. O valor nutritivo da forragem na rebrota manteve-se acima dos encontrados na primeira fase de corte. As maiores porcentagens de lâminas foram observadas nas variedades Americano e BN-2 e as maiores de hastes, na variedade AFRICANO. As melhores variedades para uso na alimentação animal são: Americano e BN2 e a melhor idade de corte é de 49 dias.

Palavras-chave: FDN, hastes, idade de corte, lâmina, proteína bruta, rebrota

\section{Forage yield and chemical composition of pearl millet varieties (Pennisetum glaucum (L.) R. BR.)}

ABSTRACT - The objective of this experiment was to evaluate the productivity, tillering, leaf blade/stem ratio and chemical composition (CP, NDF and ADF) of three pearl millet (Pennisetum glaucum (L.) R. BR.) varieties (African, American and $\mathrm{BN}-2)$ submitted to three different cutting ages (35, 42 and 49 days). During the first growth period, a splitplot arrangement in a complete randomized block design was used with varieties being the main plots and cutting ages the subplots. During regrowth, a complete randomized design was used. In both cases, there were four replications per treatment. Dry matter yield among varieties was similar (4,360, 4,204, and 3,247 kg/DM/ha) for the varieties African, American and BN-2, respectively. The CP $(15.36,16.71$, and 16.3\%), NDF $(60.55,56.29$, and 55.93\%) and ADF (34.55, 30.04, and 30.98\%) concentrations as well as the leaf blade/stem percentages differed among African, American and BN-2 varieties, respectively. Dry matter productivity, NDF, and ADF concentrations increased with the advance of cutting age while leaf blade/stem ratio and CP decreased linearly. Productivity was reduced during regrowth, however, the average CP (19.75, 20.21, and 20.43\%), $\operatorname{NDF}(52.45,53.19$, and 53.42\%) and $\operatorname{ADF}(27.44,26.72$, and 27.06\%) concentrations did not differ among African, American and BN-2 varieties during this period, respectively. The leaf blade/stem ratio, however, differed among them during regrowth. Forage nutritive value at regrowth was greater than during first growth period. American and BN-2 varieties presented the highest leaf blade percentage while the African variety showed the highest stem percentage. Thus, the best forage varieties are American and $\mathrm{BN}-2$ and the best cutting age is 49 days.

Key Words: cutting age, crude protein, leaf blade NDF, regrowth, stem 


\section{Introdução}

O milheto (Pennisetum glaucum (L.) R. BR.) é uma gramínea de origem tropical, anual de verão, de fácil implantação e manejo, que se destaca por sua adaptação a uma grande diversidade de ambientes e a diferentes condições de clima e solo, caracterizando-se por sua precocidade, seu alto potencial de produção e sua qualidade nutritiva. Quando semeado após as culturas de verão, o milheto pode ser aproveitado para colheita de grãos ou como forragem suplementar no período seco, sendo uma alternativa para suprir a carência de alimento em períodos de escassez, além de sobreviver melhor que outros cereais em solos arenosos e pouco férteis (Tabosa et al., 1999) e apresentar elevada tolerância a altas temperaturas e a períodos com déficit hídrico (Payne, 2000).

A cultura do milheto passou a se destacar no cerrado após os trabalhos de seleção iniciados em 1981, que resultaram no lançamento das variedades BN-1e BN-2 em 1986 e 1991 respectivamente. Segundo Bonamigo (1999), esses estudos contribuíram decisivamente para que, a partir de 1991, o milheto passasse a ser adotado como cobertura do solo em semeadura direta em cultura de sucessão, sendo aproveitado principalmente como pastagem e/ou silagem.

Segundo Barcellos (1999), o milheto é plantado normalmente em sobre-semeadura no final do ciclo da soja com a finalidade, dependendo da propriedade, de cobrir o solo ou alimentar o rebanho durante o período da seca. Para apresentar bom rebrote e maior produção, alguns autores recomendam o corte entre 6 e $10 \mathrm{~cm}$ do solo. Entretanto, essa altura tem como desvantagem a eliminação da maior parte das gemas basais, enquanto o corte a $20 \mathrm{~cm}$ preserva esses pontos meristemáticos (Bonamigo, 1999). Kichel et al. (1999) afirmaram que é possível produzir até $60 \mathrm{t}$ /ha de massa verde e 20 t/ha de MS de milheto em plantio realizado no início da primavera. Entretanto, quando semeado no outono, apresenta menor produtividade, observando-se produções de 4,6 t MS/ha quando colhido aos 50 dias do plantio. Benedetti (1999) também reportou produtividades de 5 a $6 \mathrm{t} \mathrm{MS/ha} \mathrm{no}$ início de sua utilização em abril. Frizzo Filho (2004), em estudo realizado em Brasília-DF, em três diferentes idades de corte (40, 50 e 60 dias), observou maiores produtividades nos cortes mais tardios, com 10.148 e $12.243 \mathrm{~kg} / \mathrm{ha} \mathrm{de} \mathrm{MS} \mathrm{aos} 50$ e 60 dias após o plantio, respectivamente. Para a rebrota, colhida 40 dias após o primeiro corte, o rendimento foi de 5.170 e $2.973 \mathrm{~kg} / \mathrm{ha}$ de MS, respectivamente. Os teores médios de PB foram de 16,08; 14,90 e 11,67\% para cortes aos 40,50 e 60 dias após o plantio e de 14,$95 ; 13,56$ e $13,73 \%$ para a rebrota, respectivamente.
O objetivo neste trabalho foi estudar o rendimento forrageiro, a composição bromatológica e a melhor idade de corte de variedades de milheto (Pennisetum glaucum (L.) R. BR.) nas condições de cerrado, no Distrito Federal.

\section{Material e Métodos}

O experimento foi instalado em 19 de março de $2004 \mathrm{em}$ um latossolo vermelho-escuro, fase argilosa profunda, com a seguinte composição química na camada de 0 a $20 \mathrm{~cm}$ : $\mathrm{pH}$ em água $=5,7 ; \mathrm{P}=3 \mathrm{mg} / \mathrm{kg}$ e $\mathrm{K}=29 \mathrm{mg} / \mathrm{kg} ; \mathrm{Ca}+\mathrm{Mg}=2,1 \mathrm{cmol} / \mathrm{kg}$; $\mathrm{Al}=0,0 \mathrm{cmol} / \mathrm{kg} ; \mathrm{H}+\mathrm{Al}=8,2 \mathrm{cmol} / \mathrm{kg}$ e $\mathrm{MO}=8 \mathrm{~g} / \mathrm{kg}$.

Os tratamentos consistiram de três variedades de milheto (Americano, Africano e BN-2) constantes no banco de germoplasma da Embrapa Cerrados, combinadas com três idades de corte (35, 42 e 49 dias). Utilizou-se o delineamento experimental em blocos casualizados, em esquema de parcelas subdivididas, com quatro repetições. Nas parcelas principais, foram distribuídas aleatoriamente as variedades e, nas subparcelas, as diferentes idades.

A área experimental compreendeu 12 parcelas principais de $60 \mathrm{~m}^{2}(4 \times 15 \mathrm{~m})$, nas quais as variedades foram semeadas em 16 linhas de $15 \mathrm{~m}$ de comprimento, a $0,25 \mathrm{~m}$ de espaçamento. As subparcelas foram constituídas pelas 16 linhas, com $5 \mathrm{~m}$ de comprimento, perfazendo $20 \mathrm{~m}^{2}$, de modo que a área útil correspondeu às oito linhas centrais, com $3 \mathrm{~m}$ de comprimento. Com base na análise do solo, aplicaram-se 3,3 t/ha de calcário dolomítico para elevar a saturação por bases a $45 \%$. A adubação de plantio consistiu de $90 \mathrm{~kg} / \mathrm{ha} \mathrm{de} \mathrm{P}_{2} \mathrm{O}_{5}$ na forma de superfosfato simples ( $58 \mathrm{~kg} / \mathrm{ha}$ de $\mathrm{K}_{2} \mathrm{O}$ ), utilizando-se cloreto de potássio, e na forma de sulfato de amônio (20 kg/ha de N), aplicados a lanço e incorporados por meio de gradagem leve.

O plantio foi realizado utilizando-se uma taxa de semeadura de $20 \mathrm{~kg} / \mathrm{ha}$ de sementes. Quando as plantas atingiram $10 \mathrm{~cm}$ de altura, realizou-se a adubação de cobertura com $60 \mathrm{~kg} / \mathrm{ha}$ de $\mathrm{Ne} 12 \mathrm{~kg} / \mathrm{ha}$ de $\mathrm{K}_{2} \mathrm{O}$, aplicando-se as mesmas fontes supracitadas. Após o primeiro corte antes do início da rebrota, repetiu-se a adubação em cobertura. Os cortes, inclusive da rebrota, foram realizados rente ao solo, na área útil de cada subparcela. Diferentemente da primeira fase, cujas avaliações envolveram cortes em diferentes idades (35, 42 e 49 dias), o vigor da rebrota foi determinado mediante o corte da forragem aos 40 dias após o primeiro corte, independentemente da idade de corte. Assim, as amostras relativas às três idades de corte foram combinadas em uma amostra composta utilizando-se o delineamento inteiramente casualizado, com quatro repetições, sem envolver a subdivisão das parcelas. 
Durante o período experimental, foram observados valores de precipitação total, temperatura média e umidade relativa do ar correspondentes a $118,2 \mathrm{~mm}, 20,1^{\circ} \mathrm{C}$ e $80,6 \%$, respectivamente, não havendo necessidade de irrigação até o final de abril. Entretanto, na primeira quinzena dos

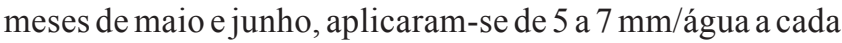
três dias para atender a necessidade de evapotranspiração e garantir o desenvolvimento normal da cultura. Atingida a fase de corte, toda a forragem constante na área útil das subparcelas correspondentes às diferentes idades $(35,42 \mathrm{e}$ 49 dias) foi cortada manualmente (rente ao solo) e pesada, com vistas à obtenção do rendimento de forragem.

As amostras foram secas em estufa de ventilação forçada $\left(60^{\circ} \mathrm{C}\right.$ por 72 horas), processadas em moinho tipo Willey e acondicionadas em frascos para análises dos teores de PB, FDN e FDA.

Para determinação da composição em lâminas e hastes, foram elaboradas amostras de 500 a $800 \mathrm{~g}$ da forragem colhida, as quais foram separadas (lâminas -lâminas foliares; hastes - caule, bainha foliar e inflorescências), secas em estufa de ventilação forçada, a $60^{\circ} \mathrm{C}$ por 72 horas, e pesadas. $\mathrm{O}$ número de perfilhos foi obtido por meio da contagem dentro da área útil de cada subparcela antes de cada corte.

Foram feitas análises de variância e regressão utilizando-se o pacote computacional Sistema de Análises Estatísticas SANEST, desenvolvido por Machado \& Zonta (1991), aplicando-se o teste Tukey a 5\% para comparação das médias.

\section{Resultados e Discussão}

Os resultados de produção de MS relativos aos cortes realizados às diferentes idades, bem como àqueles corres- pondentes à rebrota, são apresentados na Tabela 1. Na fase de cortes, independentemente da idade do corte, o rendimento não diferiu entre os genótipos, cujas médias variaram de $3.247 \mathrm{a} 4.360 \mathrm{~kg} / \mathrm{ha}$. Embora as médias de vigor da rebrota tenham sido baixas, verificaram-se diferenças significativas, de modo que o Americano foi $224 \mathrm{~kg} /$ ha inferior $(\mathrm{P}>0,05)$ ao BN-2, que produziu $564 \mathrm{~kg} / \mathrm{ha}$, enquanto o Africano apresentou produtividade intermediária, $410 \mathrm{~kg} / \mathrm{ha}$, não diferindo dos demais cultivares avaliados.

Quanto às idades de corte, no intervalo estudado, a análise de regressão indicou comportamento linear $(\mathrm{P}<0,05)$ crescente, ou seja, aumentos nas quantidades produzidas com o decorrer da estação de crescimento. Como não houve interação variedade $\times$ idade de corte, a curva de regressão (Figura 1) corresponde à média das três variedades.

Os valores médios de produção ajustados pela equação de regressão foram de 2.205,5; $3.936,9$ e $5.668,4$ kg/ha para o corte aos 35,42 e 49 dias, respectivamente. As produtividades observadas aos 35 e 42 dias corresponderam, respectivamente, a 42,6 e 53,0\% da obtida aos 49 dias de idade. Portanto, do ponto de vista do rendimento forrageiro, a idade de corte mais apropriada foi aos 49 dias.

De modo geral, esses resultados podem ser considerados satisfatórios, sendo semelhantes aos observados por Kichel et al. (1999), de 4,6 t MS/ha, em colheitas feitas no outono, aos 50 dias de idade, e Guterres et al. (1976) e Benedetti (1999), de 5 a 6 t/ha em cortes realizados no início de abril. Foram superiores, no entanto, aos verificados por Isepon \& Matsumoto (1999), com plantio também em março, que obtiveram produção de $2,167 \mathrm{~kg} / \mathrm{ha}$, e inferiores aos observados por Pereira et al. (1993), de 8,4 t/ha a 9,6 t/ha de MS quando fizeram os cortes aos 64 aos 100 dias.

Tabela 1 - Produção de MS (kg/ha) de três variedades de milheto (Pennisetum glaucum (L.) R. BR.) submetidas ao corte aos 35, 42 e 49 dias de idade e da rebrota após 40 dias de crescimento

Table 1 - Dry matter yield (kg/ha) of three pearl millet varieties (Pennisetum glaucum (L.) R. Br.) submitted to different cutting ages (35, 42 and 49 days), and productivity after 40 days of regrowth

\begin{tabular}{|c|c|c|c|c|c|c|c|}
\hline \multirow[t]{2}{*}{$\begin{array}{l}\text { Variedade } \\
\text { Variety }\end{array}$} & \multicolumn{5}{|c|}{$\begin{array}{l}\mathrm{MS}(\mathrm{kg} / \mathrm{ha}) \\
D M(\mathrm{~kg} / \mathrm{ha})\end{array}$} & \multicolumn{2}{|c|}{$\begin{array}{c}\text { Rebrota MS }(\mathrm{kg} / \mathrm{ha}) \\
\text { DM regrowth }(\mathrm{kg} / \mathrm{ha})\end{array}$} \\
\hline & 35 & 42 & 49 & $\begin{array}{l}\text { Média }^{1} \\
\text { Mean }\end{array}$ & $\mathrm{CV}^{3}(\%)$ & $\begin{array}{l}\text { Média }^{1} \\
\text { Mean }\end{array}$ & $\mathrm{CV}^{3}(\%)$ \\
\hline Africano & 2.937 & 3.918 & 6.224 & $4.360 \mathrm{~A}$ & 71,90 & $410 \mathrm{AB}$ & 47,89 \\
\hline $\begin{array}{l}\text { African } \\
\text { Americano }\end{array}$ & 2.747 & 3.013 & 6.854 & $4.204 \mathrm{~A}$ & 55,72 & $224 \mathrm{~B}$ & 57,83 \\
\hline $\begin{array}{l}\text { American } \\
\mathrm{BN}-2\end{array}$ & 2.038 & 2.669 & 5.032 & $3.247 \mathrm{~A}$ & 60,36 & $564 \mathrm{~A}$ & 42,60 \\
\hline $\begin{array}{l}\text { Média } \\
\text { Mean }\end{array}$ & $2.574^{2}$ & $3.200^{2}$ & $6.037^{2}$ & & & & \\
\hline
\end{tabular}

${ }^{1}$ Médias seguidas de pelo menos uma mesma letra maiúscula nas colunas não diferem entre si pelo teste Tukey a $5 \%$.

2 Efeito linear $(P<0,05)$.

3 Coeficiente de variação.

${ }^{1}$ Means followed by at least one capital letter within the same column do not differ by Tukey test at $5 \%$.

2 Linear response $(P<0.05)$

3 Coefficient of variation. 


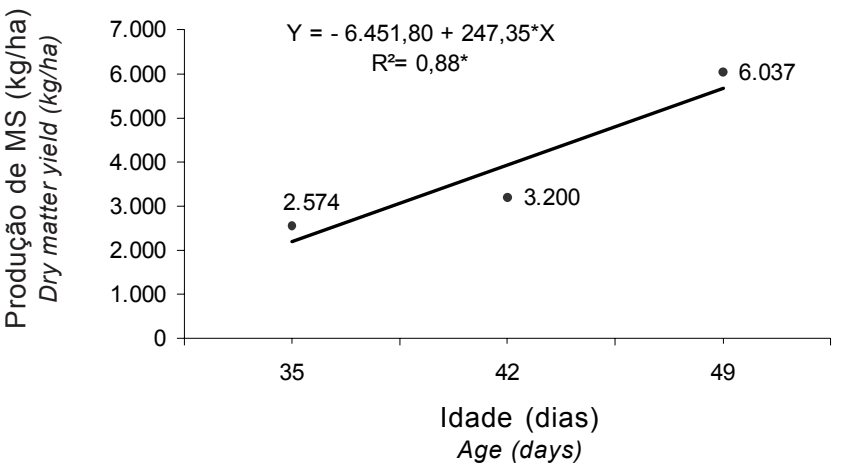

Figura 1 - Produção de MS (kg/ha) das variedades de milheto (Pennisetum glaucum (L.) R. Br.) em três idades de corte (35, 42 e 49 dias de idade).

Figure 1 - Dry matter yield ( $\mathrm{kg} / \mathrm{ha}$ ) of pearl millet varieties (Pennisetum glaucum (L.) R. Br.) in three different cutting ages (35, 42 and 49 days).

Não houve efeito da interação $(P>0,05)$ variedades $x$ idades de corte sobre o número de perfilhos e as porcentagens de lâminas e hastes (Tabela 2).

Os resultados demonstraram que o número médio de perfilhos diferiu $(\mathrm{P}<0,05)$ entre as variedades, de modo que o cultivar Africano apresentou 115 perfilhos $/ \mathrm{m}^{2}$ a mais que o Americano (96 perfilhos $/ \mathrm{m}^{2}$ ) e BN-2 (90 perfilhos $/ \mathrm{m}^{2}$ ), que não diferiram entre si. Entretanto, esse maior número de perfilhos não resultou em diferença na produtividade (Tabela 2), provavelmente em razão da diferença no peso dos perfilhos entre as variedades estudadas.

Não houve diferença $(\mathrm{P}>0,05)$ no número de perfilhos entre as idades de corte estudadas (Figura 2), cujas médias ajustadas pela equação de regressão foram de 102,100 e 98 perfilhos $/ \mathrm{m}^{2}$, aos 35, 42 e 49 dias de idade, respectivamente. Essas informações, em comparação àquelas relacionadas à elevação na produtividade com o avanço da idade (Figura 1), indicam que o fator número de perfilhos não foi importante na produtividade.

Nesse sentido, Coelho (1999) afirma que o número de perfilhos por si só não permite uma informação concreta da capacidade produtiva de uma forrageira, pois há uma relação inversa entre o número de perfilhos e seu peso seco individual. Assim, a densidade de perfilhos pode ser utilizada como parâmetro da produtividade, devendo ser analisados, portanto, os componentes da produção, em razão do aumento em número e peso de perfilhos.

Os resultados da proporção de lâminas e hastes não demonstraram efeito de interação variedades $\times$ idades de corte. Verificou-se que as variedades diferiram $(\mathrm{P}<0,05)$ entre si quanto às porcentagens médias de lâminas e de hastes. As variedades Americano e BN-2, cujas médias foram, respectivamente, de 48 e $45 \%$ de lâminas foliares e de 52 e $55 \%$ de hastes, superaram o Africano (34 e 66\% de lâminas e hastes, respectivamente). As melhores relações lâmina/haste são indicadoras de boas características forrageiras e representam forragens qualitativamente superiores, tendo em vista os mais elevados teores de proteína e a digestibilidade das lâminas em relação às hastes, resultando em maior consumo. Comparando as porcentagens médias de lâminas foliares e de hastes nas diferentes idades de corte, verificou-se que, com o avanço da idade das plantas, houve redução linear $(\mathrm{P}<0,05)$ do componente lâmina (Figura 3) e elevação linear $(\mathrm{P}<0,05)$ na porcentagem de hastes (Figura 4). Este comportamento era esperado, pois, à medida que as plantas se desenvolvem, ocorrem

Tabela 2 - Número de perfilhos $/ \mathrm{m}^{2}$ e porcentagens de lâminas e hastes de três variedades de milheto (Pennisetum glaucum (L.) R.Br.) em três idades de corte (35, 42 e 49 dias de idade)

Table 2 - Number of tillers $/ \mathrm{m}^{2}$ and percentages of leaf blade and stem of three pearl millet varieties (Pennisetum glaucum (L.) R. Br.) in three different cutting ages (35, 42 and 49 days)

\begin{tabular}{|c|c|c|c|c|c|c|c|c|c|c|c|c|c|c|c|}
\hline \multirow[t]{2}{*}{$\begin{array}{l}\text { Variedade } \\
\text { Variety }\end{array}$} & \multicolumn{5}{|c|}{$\begin{array}{l}\text { № de perfilhos } / \mathrm{m}^{2} \\
N \text {. of tiller } / \mathrm{m}^{2}\end{array}$} & \multicolumn{5}{|c|}{$\begin{array}{l}\text { \% de lâmina } \\
\text { Leaf blade (\%) }\end{array}$} & \multicolumn{4}{|c|}{$\begin{array}{l}\% \text { de haste } \\
\text { Stem (\%) }\end{array}$} & \multirow[b]{2}{*}{$\mathrm{CV}^{5}(\%)$} \\
\hline & 35 & 42 & 49 & $\begin{array}{l}\text { Média }^{1} \\
\text { Mean }^{1}\end{array}$ & $\mathrm{CV}^{5}(\%)$ & 35 & 42 & 49 & $\begin{array}{l}\text { Média }^{1} \\
\text { Mean }^{1}\end{array}$ & $\mathrm{CV}^{5}(\%)$ & 35 & 42 & 49 & $\begin{array}{l}\text { Média }^{1} \\
\text { Mean }^{1}\end{array}$ & \\
\hline $\begin{array}{l}\text { Africano } \\
\text { African }\end{array}$ & 120 & 114 & 112 & $115 \mathrm{~A}$ & 9,20 & 47 & 36 & 20 & $34 \mathrm{~B}$ & 25,30 & 53 & 64 & 80 & $66 \mathrm{~A}$ & 22,08 \\
\hline $\begin{array}{l}\text { Americano } \\
\text { American }\end{array}$ & 98 & 101 & 90 & $96 \mathrm{~B}$ & 10,09 & 53 & 61 & 29 & $48 \mathrm{~A}$ & 23,37 & 47 & 39 & 71 & $52 \mathrm{~B}$ & 22,61 \\
\hline $\mathrm{BN}-2$ & 89 & 85 & 95 & $90 \mathrm{~B}$ & 13,99 & 62 & 48 & 26 & $45 \mathrm{~A}$ & 13,16 & 38 & 52 & 74 & $55 \mathrm{~B}$ & 18,11 \\
\hline $\begin{array}{l}\text { Média } \\
\text { Mean }\end{array}$ & $102^{2}$ & $100^{2}$ & $99^{2}$ & & & $54^{3}$ & $48^{3}$ & $25^{3}$ & & & $46^{4}$ & $52^{4}$ & $75^{4}$ & & \\
\hline
\end{tabular}

Médias seguidas de pelo menos uma mesma letra maiúscula nas colunas não diferem entre si pelo teste Tukey a $5 \%$.

Efeito linear $(P>0,05)$.

4 Efeito linear $(P<0,05)$.

Coeficiente de variação.

Means followed by at least one capital letter within the columns do not differ by Tukey test at $5 \%$.

Linear response $(P>0.05)$.

4 Quadratic response $(P<0.05)$

Coefficient of variation. 


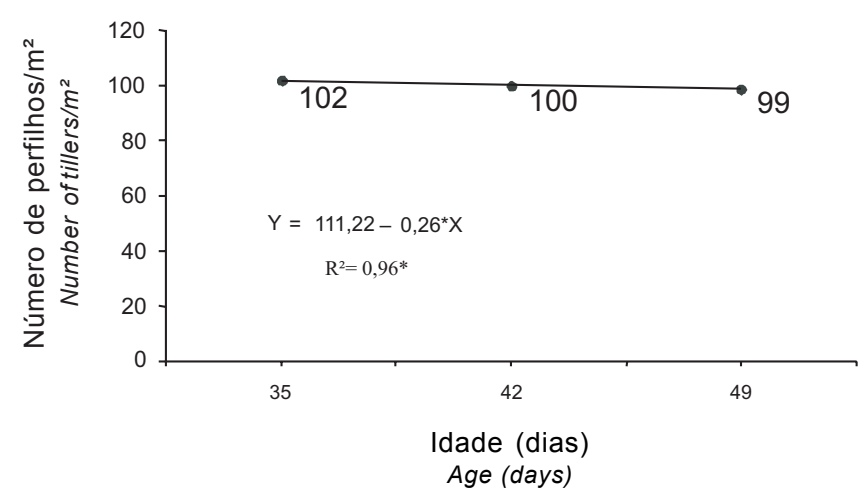

Figura 2 - Número de perfilhos $/ \mathrm{m}^{2}$ das variedades de milheto (Pennisetum glaucum (L.) R. Br.) em três idades de corte (35, 42 e 49 dias).

Figure 2 - Number of tiller $/ \mathrm{m}^{2}$ of pearl millet varieties (Pennisetum glaucum (L.) R. Br.) in three different cutting ages $(35,42$ and 49 days).

ajustes morfológicos que refletem expressivamente na produtividade e no valor nutritivo da forragem. Os valores médios de participação de lâminas ajustados pela equação de regressão foram de 57,43 e $28 \%$ para os cortes aos 35,42 e 49 dias, respectivamente, enquanto as hastes representaram 43,57 e $72 \%$ nas mesmas idades.

Os resultados relativos ao número de perfilhos e às porcentagens de lâminas e hastes obtidos na rebrota são apresentados na Tabela 3. O número médio de perfilhos diferiu $(\mathrm{P}<0,05)$ entre as variedades, de modo que os cultivares BN-2 e Africano ( 74 e 73 perfilhos $/ \mathrm{m}^{2}$ ) foram superiores ao Americano (44 perfilhos $/ \mathrm{m}^{2}$ ). O maior número de perfilhos resultou em diferença na produtividade. Conforme Kramer (1983), geralmente todos os aspectos ligados ao crescimento da planta são afetados pelo estresse hídrico, sendo freqüentemente citados na literatura inibição do perfilhamento e das ramificações, aceleração da morte dos perfilhos estabelecidos (Buxton \& Fales, 1994) e atraso no crescimento e desenvolvimento da planta (Hsiao \& Acevedo, 1975).

As porcentagens médias de lâminas e hastes da rebrota diferiram $(\mathrm{P}<0,05)$ entre as variedades. $\mathrm{O}$ cultivar Americano, com $73 \%$ de lâminas $27 \%$ de hastes, superou o Africano, que apresentou 62 e 38\% de lâminas e hastes. $\mathrm{O}$ cultivar BN-2, no entanto, não diferiu dos demais. Quando se estabeleceu a relação lâmina/haste, o pior valor médio (1,6:1) foi observado para o cultivar Africano, enquanto o Americano e o BN-2 apresentaram valores médios de 2,7:1 e 2,03:1, respectivamente, o que significa que variedades com maior relação lâmina/haste apresentam maior potencial para utilização como forragem. Na rebrota, em comparação à fase de corte, houve incremento de $159 \%$ na média de lâminas e decréscimo de $56,8 \%$ na de hastes (Tabelas 2 e 3 ).

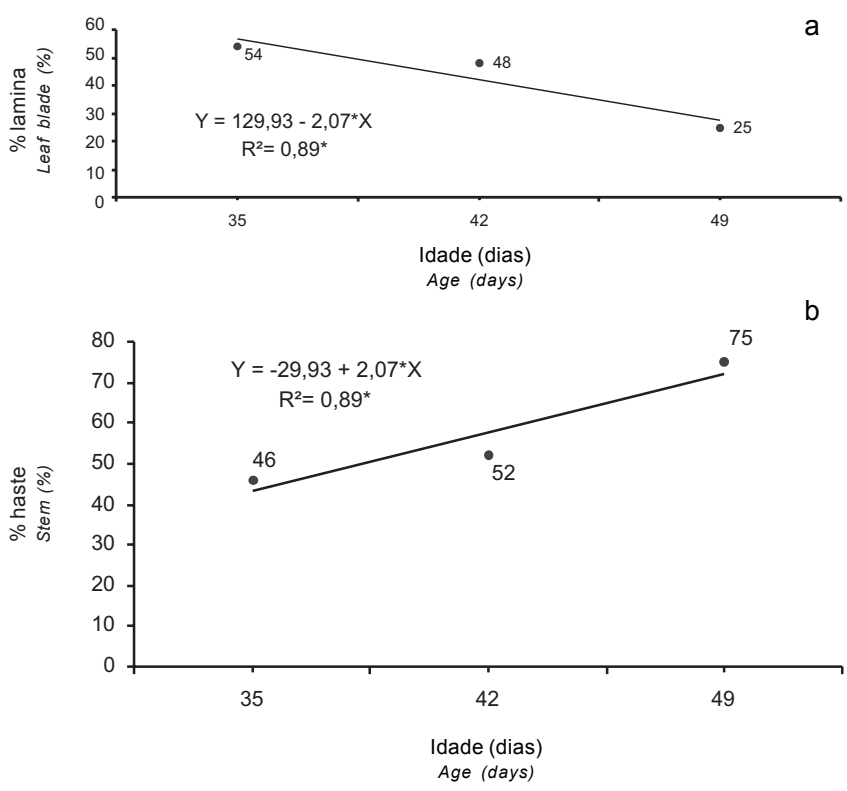

Figura 3 - Porcentagem de lâminas (a) e hastes (b) de variedades de milheto (Pennisetum glaucum (L.) R.Br.) em três idades de corte (35, 42 e 49 dias).

Figure 3 - Percentage of leaf blade (a) and stem (b) of pearl millet varieties (Pennisetum glaucum (L.) R. Br.) in three different cutting ages (35, 42 and 49 days).

Os resultados relativos aos conteúdos de $\mathrm{PB}, \mathrm{FDN}$ e FDA para as diferentes idades de corte são apresentados na Tabela 4. Para nenhuma dessas variáveis, houve efeito de interação $(\mathrm{P}>0,05)$ variedades $\times$ idades de corte.

$\mathrm{O}$ teor de $\mathrm{PB}$ diferiu $(\mathrm{P}<0,05)$ entre as variedades; o cultivar Americano apresentou 16,71\%, o Africano 15,36\% e o BN2 16,30\% (valor intermediário), não diferindo dos dois anteriores. Estes resultados são bastante próximos aos encontrados na literatura, como aqueles reportados por Isepon \& Matsumoto (1999), de 17,9\% para a mesma época de semeadura, e Frizzo Filho (2004), de 14,21\% de PB para a semeadura de verão. Respaldam, no entanto, a idéia de que o cultivar Americano é uma espécie com alto potencial para uso na alimentação animal, tanto por sua capacidade de produção como pela qualidade nutricional, superando diversas outras forrageiras tropicais.

Comparando a porcentagem de PB nas diferentes idades de corte (Figura 6), observa-se que os valores reduziram de forma quadrática $(\mathrm{P}<0,05)$ com o avançar do estádio de desenvolvimento.

Os valores ajustados pela equação de regressão foram de 19,33; 15,42 e 13,62\% para 35, 42 e 49 dias de idade, respectivamente, e confirmam os obtidos por Antunes et al. (1999), de 21,33 e $13,51 \%$ de PB aos 37 e 52 dias de idade, com redução nos teores de $\mathrm{PB}$ à medida que foram aumentados os intervalos de cortes. 
Tabela 3 - Número de perfilhos $/ \mathrm{m}^{2}$ e porcentagem de lâminas e hastes de três variedades de milheto (Pennisetum glaucum (L.) R.Br.) na rebrota

Table 3 - N Number of tillers $/ \mathrm{m}^{2}$ and percentages of leaf blade and stem of three pearl millet varieties (Pennisetum glaucum (L.) R. Br.) during regrowth

\begin{tabular}{|c|c|c|c|c|c|c|}
\hline $\begin{array}{l}\text { Variedade } \\
\text { Variety }\end{array}$ & $\begin{array}{c}\text { № perfilhos } / \mathrm{m}^{2} \\
N \text {. of tillers } / \mathrm{m}^{2}\end{array}$ & $\mathrm{CV}^{2}(\%)$ & $\begin{array}{l}\text { \% de lâmina } \\
\text { Leaf blade (\%) }\end{array}$ & $\mathrm{CV}^{2}(\%)$ & $\begin{array}{l}\% \text { de haste } \\
\text { Stem (\%) }\end{array}$ & $\mathrm{CV}^{2}(\%)$ \\
\hline & $\begin{array}{l}\text { Média } \\
\text { Mean }^{1}\end{array}$ & & $\begin{array}{l}\text { Média } \\
\text { Mean }^{1}\end{array}$ & & $\begin{array}{l}\text { Média } \\
\text { Mean }^{1}\end{array}$ & \\
\hline $\begin{array}{l}\text { Africano } \\
\text { African }\end{array}$ & $73 \mathrm{~A}$ & 48,99 & $62 \mathrm{~B}$ & 9,97 & $38^{A}$ & 11,40 \\
\hline $\begin{array}{l}\text { Americano } \\
\text { American }\end{array}$ & $44 \mathrm{~B}$ & 45,09 & $73 \mathrm{~A}$ & 10,90 & $27 \mathrm{~B}$ & 11,34 \\
\hline $\mathrm{BN}-2$ & $74 \mathrm{~A}$ & 36,62 & $67 \mathrm{AB}$ & 8,59 & $33 \mathrm{AB}$ & 9,82 \\
\hline $\begin{array}{l}\text { Média } \\
\text { Mean }\end{array}$ & 63 & & 67 & & 33 & \\
\hline
\end{tabular}

${ }^{1}$ Médias seguidas de pelo menos uma mesma letra maiúscula nas colunas não diferem entre si pelo teste Tukey a $5 \%$.

2 Coeficiente de variação.

${ }^{1}$ Means followed by at least one capital letter within the columns do not differ by Tukey test at $5 \%$.

2 Coefficient of variation.

Tabela 4 - Teores (\%) de PB, FDN e FDA de três variedades de milheto (Pennisetum glaucum (L.) R. Br.) submetidas a três idades de corte $(35,42$ e 49 dias)

Table 4 - Contents (\%) of CP, NDF and ADF of three pearl millet varieties (Pennisetum glaucum (L.) $R$ Br.) submitted to three different cutting ages (35, 42 and 49 days)

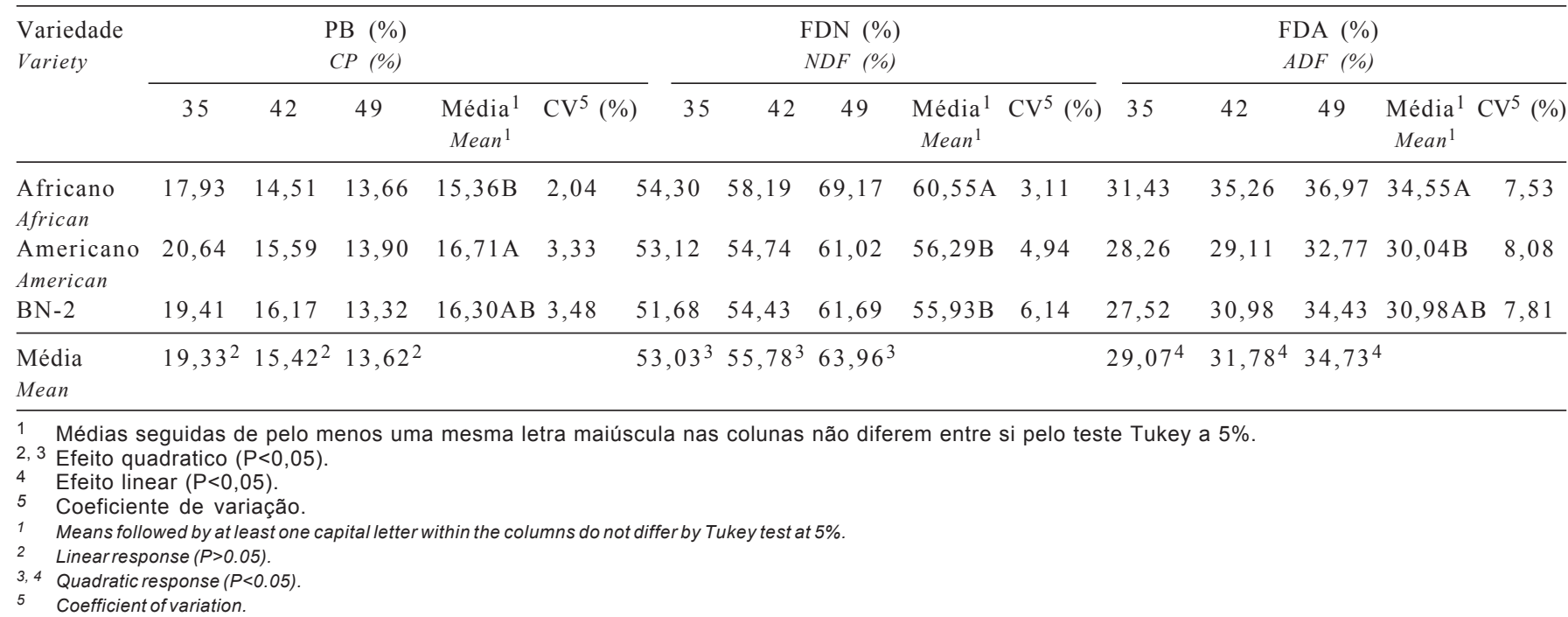

O conteúdo de FDN diferiu $(\mathrm{P}<0,05)$ entre as variedades. O cultivar Africano apresentou $60,55 \%$ e o Americano e BN2, 56,29 e 55,93\% de FDN, respectivamente. Estes resultados são bastante próximos aos descritos na literatura, como aqueles reportados por Isepon \& Matsumoto (1999), que encontraram $58,8 \%$ de FDN para a mesma época de semeadura, e Frizzo Filho (2004), que observou valor médio de 59,64\% de FDN com semeadura no verão de 2003.

Comparando a porcentagem de FDN para as diferentes idades de corte, verificou-se que seu teor aumentou de forma quadrática $(\mathrm{P}<0,05)$, conforme ilustrado na Figura 7 . Os valores ajustados pela equação de regressão foram de 53,$03 ; 55,78$ e $63,95 \%$ para 35,42 e 49 dias de idade, respectivamente, o que pode ser justificado pelo fato de o conteúdo de FDN aumentar com o avançar da idade da planta, provavelmente em virtude da redução da porcentagem de lâminas e do aumento da proporção de hastes, elevando os componentes fibrosos.

Houve diferença $(\mathrm{P}<0,05)$ no conteúdo de FDA entre as variedades estudadas. O teor de FDA da variedade Africano (34,55\%) foi superior ao verificado para o Americano $(30,04 \%)$, ao passo que o BN2 apresentou valor intermediário (30,98\%), não diferindo dos demais. Estes resultados são bastante próximos aos reportados por Maia et al. (2000), de 42,27\% de FDA, em mesma época de semeadura. Resultados semelhantes foram verificados no verão por Frizzo Filho (2004), que encontrou valores médios de 32,15\%. Os teores de FDA aumentaram de forma linear $(\mathrm{P}<0,05)$ com as idades de corte (Figura 8$)$. Os valores ajustados pela equação de regressão foram de 


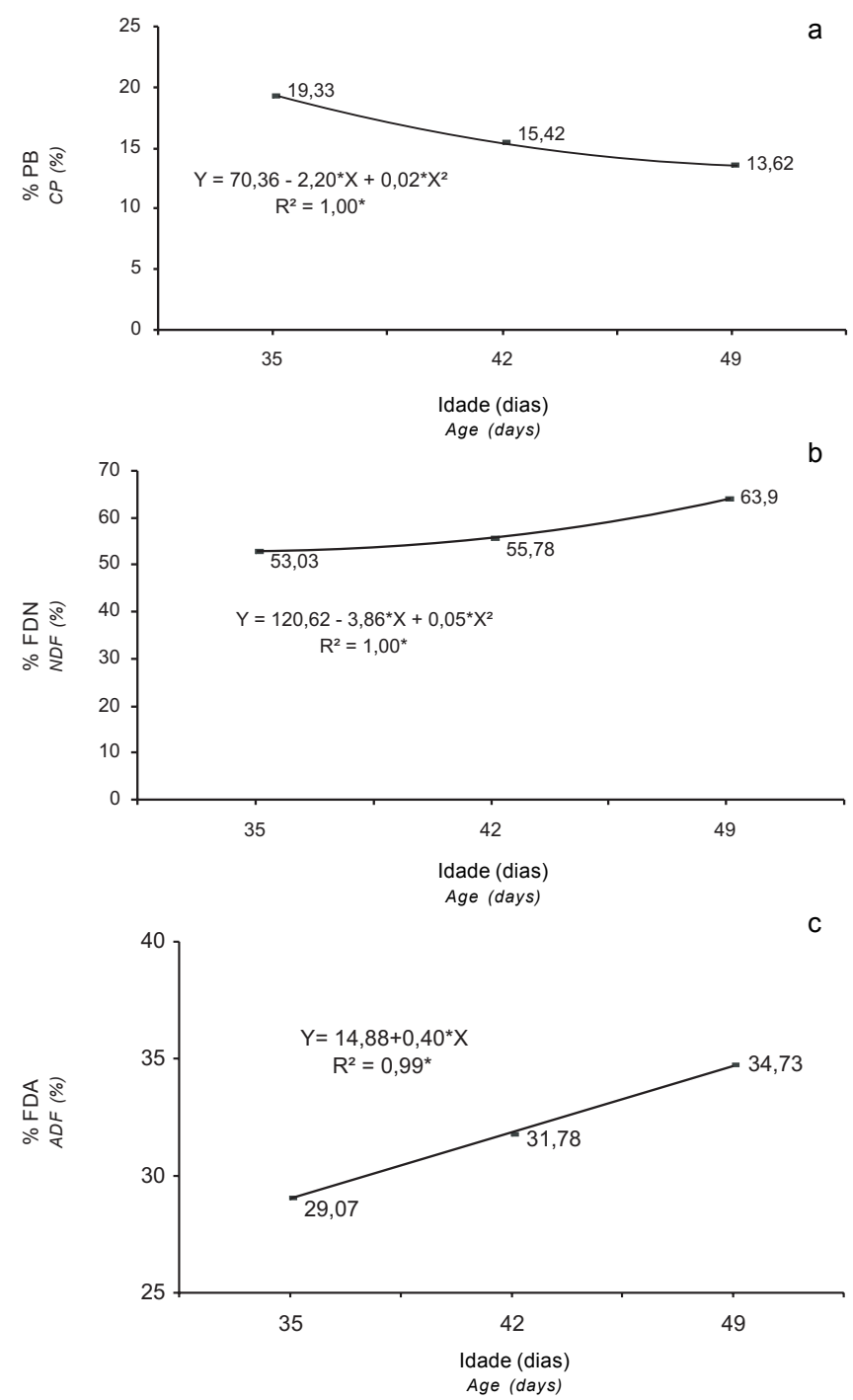

Figura 4 - Teores (\%) de PB (a), FDN (b) e FDA (c) de variedades de milheto (Pennisetum glaucum (L.) R. Br.) em três idades de corte (35, 42 e 49 dias)

Figure 4 - Contents of CP (a), NDF (b) and $A D F(c)$ of pearl millet varieties (Pennisetum glaucum (L.) R. Br.) in three different cutting ages (35, 42 and 49 days).
29,06; 31,78 e 34,73\% para 35, 42 e 49 dias de idade, respectivamente.

Esse comportamento foi constatado por Maia et al. (2000), que verificaram teores de FDA mais elevados para o milheto colhido em idade mais avançada, o que pode estar associado à elevação dos constituintes fibrosos com o avançar da idade da planta, verificando-se a mesma tendência para o conteúdo de FDA. Assim, a idade de corte adequada, considerando unicamente o teor de FDA, seria 35 dias de idade (Figura 8).

Os resultados referentes aos conteúdos de PB, FDN e FDA para a rebrota são apresentados na Tabela 5. Não houve diferença $(\mathrm{P}<0,05)$ no conteúdo de $\mathrm{PB}$ entre as variedades. O teor de PB da variedade Americano, de $20,21 \%$, foi similar ao das variedades BN-2 e Africano, de 20,43 e $19,75 \%$, respectivamente.

Estes resultados são superiores aos observados por Pereira et al. (1993), de 16,7\% de PB, e Antunes (1999), de 18,29\% de PB, durante a rebrota. Resultados superiores foram encontrados por Kichel et al. (1999), que relataram ser possível atingir $24 \%$ de $\mathrm{PB}$ em condições de pastejo. Nelson $\&$ Moser (1994) afirmaram que seca prolongada geralmente resulta em plantas com maior relação folha/caule e, conseqüentemente, com maiores teores de proteína e mais alta digestibilidade.

Não houve diferença $(\mathrm{P}>0,05)$ no conteúdo de FDN entre as variedades, sendo observados valores de 52,45; 53,19 e $53,42 \%$, respectivamente, para as variedades Africano, Americano e BN-2. Estes resultados são inferiores aos encontrados na literatura, como aqueles reportados por Isepon \& Matsumoto (1999), de 58,8\% de FDN, e Maia et al., (2000), de 64,87\% de FDA, para a mesma época de plantio.

Não foi observada diferença $(\mathrm{P}>0,05)$ no conteúdo de FDA entre as variedades. Observaram-se para os cultivares

Tabela 5 - Teores (\%) de PB, FDN e FDA de três variedades de milheto (Pennisetum glaucum (L.) R. Br.) na rebrota Table 5 - Contents (\%) of CP, NDF and ADF of three pearl millet varieties (Pennisetum glaucum (L.) R. Br.) during regrowth

\begin{tabular}{|c|c|c|c|c|c|c|}
\hline $\begin{array}{l}\text { Variedade } \\
\text { Variety }\end{array}$ & $\begin{array}{c}\text { PB (\%) } \\
C P(\%)\end{array}$ & $\mathrm{CV}^{2}(\%)$ & $\begin{array}{c}\text { FDN }(\%) \\
N D F(\%)\end{array}$ & $\mathrm{CV}^{2}(\%)$ & $\begin{array}{c}\text { FDA }(\%) \\
A D F(\%)\end{array}$ & $\mathrm{CV}^{2}(\%)$ \\
\hline & $\begin{array}{l}\text { Média }^{1} \\
\text { Mean }^{1}\end{array}$ & & $\begin{array}{c}\text { Média }^{1} \\
\text { Mean }^{1}\end{array}$ & & $\begin{array}{l}\text { Média }^{1} \\
\text { Mean }^{1}\end{array}$ & \\
\hline $\begin{array}{l}\text { Africano } \\
\text { African }\end{array}$ & $19,75^{\mathrm{A}}$ & 1,23 & $52,45^{\mathrm{A}}$ & 3,07 & $27,44^{\mathrm{A}}$ & 7,51 \\
\hline $\begin{array}{l}\text { Americano } \\
\text { American }\end{array}$ & $20,21^{\mathrm{A}}$ & 1,10 & $53,19^{\mathrm{A}}$ & 2,13 & $26,72^{\mathrm{A}}$ & 9,96 \\
\hline $\begin{array}{l}\text { Média } \\
\text { Mean }\end{array}$ & 20,13 & & 53,02 & & 27,08 & \\
\hline
\end{tabular}

${ }^{1}$ Médias seguidas de pelo menos uma mesma letra maiúscula nas colunas não diferem entre si pelo teste Tukey a $5 \%$.

2 Coeficiente de variação.

${ }^{1}$ Means followed by at least one capital letter within the columns do not differ by Tukey test at $5 \%$.

2 Coefficient of variation. 
Africano, Americano e BN-2 valores de 27,44; 26,72 e $27,06 \%$, respectivamente, que são inferiores aos descritos na literatura, como os reportados por Maia et al. (2000), de $39,73 \%$ de FDA para a mesma época de semeadura.

De modo geral, na rebrota, os teores médios de $\mathrm{PB}$ aumentaram e os de FDN e FDA diminuíram, o que caracteriza o bom valor nutritivo do milheto e reflete seu potencial para utilização como forragem.

\section{Conclusões}

As variedades estudadas se equivaleram em rendimento forrageiro e composição bromatológica, mas as variedades Americano e BN-2 destacaram-se por apresentar melhor relação folha:haste em relação à variedade Africano.

Os maiores rendimentos foram obtidos nos cortes efetuados aos 49 dias de idade, enquanto a qualidade da forragem foi superior aos 35 dias de idade. Recomenda-se 49 dias como a melhor idade de corte, uma vez que, nesse estádio de desenvolvimento, o acúmulo de forragem foi proporcionalmente maior que a redução na qualidade.

\section{Agradecimento}

Ao Conselho Nacional de Desenvolvimento Científico e Tecnológico - CNPq, pela concessão da bolsa de estudo que viabilizou a realização deste trabalho.

\section{Literatura Citada}

ANTUNES, R.C.; GONCALVES, L.C.; RODRIGUEZ, J.A.S. et al. Teores de matéria seca total, proteína bruta e digestibilidade in vitro da matéria seca do feno de três genótipos de milheto (Pennisetum glaucum), em diferentes idades de corte. In: REUNIÃO ANUAL DA SOCIEDADE BRASILEIRA DE ZOOTECNIA, 36., 1999, Porto Alegre. Anais... Porto Alegre: Sociedade Brasileira de Zootecnia, 1999 (CD-ROM).

BARCELLOS, A.O.; VIANA FILHO, A.; BALBINO, L.C. Restabelecimento de capacidade produtiva e desempenho animal em pastagem renovadas na região do cerrado. Planaltina: Embrapa Cerrados, 1999. 40p (Comunicado Técnico, 22).

BENEDETTI, E. Uso do milheto como fonte alternativa de produção de leite à pasto. In: WORKSHOP INTERNACIONAL DO MILHETO, 1999, Brasília. Anais... Brasília: Jica-Embrapa, 1999. p. 105-108.

BONAMIGO, L.A. A cultura de milheto no Brasil, implantação e desenvolvimento no cerrado. In: WORKSHOP INTERNACIONAL DO MILHETO, 1999, Brasília. Anais... Brasília: Jica-Embrapa, 1999. p.51.

BUXTON, D.R.; FALES, S.L. Plant environment and quality. In: FAHEY JR.; G.C. (Ed.) Forage quality, evaluation and utilization. Madison: American Society of Agronomy, 1994. p.155-199.

COELHO, E.M.; CECATO, U.; BARBOSA, M.A.F. et al Características do perfilhamento em quatro cultivares de Panicum maximum Jacq (1). In: REUNIÃO DA SOCIEDADE BRASILEIRA DE ZOOTECNIA, 36., 1999, Porto Alegre. Anais... Porto Alegre: Sociedade Brasileira de Zootecnia, 1999 (CD-ROM)

FRIZZO FILHO, O. Produtividade e composição química de variedades de milheto (Pennisetum glaucum (L.) R. BR.) em diferentes idades de corte visando a fenação. Brasília: Universidade de Brasília, 2004. 38p. Dissertação (Mestrado em Ciências Agrárias) - Universidade de Brasília, 2004.

GUTERRES, E.P.; SAIBRO, J.C.; GOMES, D.B. et al. Manejo em milheto e sorgo para pastejo. Anuário Técnico do Instituto de Pesquisas Zootécnicas Francisco, v.3, p.305-316, 1976.

HSIAO, T.C.; ACEVEDO, E. Plant responses to water déficits-use efficiency, and drought resistence. In: STONE, J.F. (Ed.) Plant modification for more efficient water use. Amsterdam: Elsevier Scientific Publishing Company, 1975. p.59-84.

ISEPON, O.J.; MATSUMOTO, E. Produção e qualidade de milheto (Pennisetum americanum (L) Leeke) em diferentes espaçamentos e épocas de plantio. In: REUNIÃO ANUAL DA SOCIEDADE BRASILEIRA DE ZOOTECNIA, 36., 1999, Porto Alegre. Anais... Porto Alegre: Sociedade Brasileira de Zootecnia, 1999 (CD-ROM).

KICHEL, A.N.; MIRANDA, C.H.B.; SILVA, J.M. O milheto (Pennisetum americanum (L.) Leek) como planta forrageira. In: WORKSHOP INTERNACIONAL DO MILHETO, 1999, Brasília. Anais... Brasília: Jica-Embrapa, 1999. p.97-103.

KRAMER, P.J. Water relations of plants. New York: Academic Press, 1983. 489p.

MACHADO, A.A.; ZONTA, E.P. Manual do Sanest: sistema de análise estatística para microcomputadores. Pelotas: Universidade Federal de Pelotas, 1991. 102p.

MAIA, M.C.; PINTO, J.C. ANDRADE, I.F. Estabelecimento de pastagem de capim-tanzânia usando milheto como cultura acompanhante. Revista Brasileira de Zootecnia, v.29, n.5, p.1312-1319, 2000.

MAIA, M.C.; PINTO, J.C.; EVANGELISTA, A.R. Concentração de fibras (FDN e FDA) e minerais de cultivares de milheto em sucessão à cultura de feijão no sul de Minas Gerais. Ciência Animal Brasileira, v.1, n.1, p.23-29, 2000.

NÉLSON, C.J.; MOSER, L.E. Plant factors affecting forage quality. In: FAHEY JR., G.C. (Ed.) Forage quality evaluation and utilization. Madison: American Society of Agronomy, 1994 p. $115-154$

PAYNE, W.A. Optimizing crop water use in sparse stands of pearl millet. Crop Science, v.92, p.808-814, 2000.

PEREIRA, O.G.; OBEID, J.A.; GOMIDE, J.A. et al. Produtividade e valor nutritivo de Aveia (Avena sativa), milheto (Pennisetum americanum ( L.) e de um híbrido de Sorghum bicolor $\mathrm{x}$ S. sorgo sudanense. Revista da Sociedade Brasileira de Zootecnia, v.22, n.1, p.22-30, 1993

TABOSA, J.N.; BRITO. A.R.M.B.; LIMA, G.S. et al. Perspectivas do milheto no Brasil - Região Nordeste. In: WORKSHOP INTERNACIONAL DO MILHETO, 1999, Brasília. Anais... Brasília: Jica-Embrapa, 1999. p.169-185.

THIAGO, L.R.L.; SILVA, J.M.; GOMIDE. R.F.C. et al. Pastejo de milheto e aveia para recria e engorda de bovinos. Campo Grande: Embrapa CNPGC, 1997. 33p (Boletim de Pesquisa, 6)

Recebido: 05/0505 